\title{
Association between Serum Vitamin D Levels and Basal Cell
} Carcinoma (BCC)

\author{
Abbas Darjani, ${ }^{1}$ Seyyed Mojtaba Mehrdad, ${ }^{2}$ Tayebeh Rezazadeh Zahedi, ${ }^{1}$ Narges Alizadeh, ${ }^{1}$ Hojat \\ Eftekhari, ${ }^{1}$ Rana Rafiee, ${ }^{1}$ Nahid Nikkhah, ${ }^{3}$ Kaveh Gharaei Nejad, ${ }^{1}$ and Zahra Mohtasham Amiri ${ }^{4,}$ \\ ${ }^{1}$ Skin Research Center, Guilan University of Medical Sciences, Rasht, Iran \\ ${ }^{2}$ Department of Internal Medicine, Razi Hospital, Guilan University of Medical Sciences, Rasht, Iran \\ ${ }^{3}$ Skin and Stem Cell Research Center, Tehran University of Medical Sciences, Tehran, Iran \\ ${ }^{4}$ Department of Social Medicine and Preventive Medicine, Guilan University of Medical Sciences, Rasht, Iran \\ "Corresponding author: Zahra Mohtasham Amiri, Department of Social Medicine and Preventive Medicine, Guilan University of Medical Sciences, Rasht, Iran. E-mail: \\ mohtashamaz@yahoo.com
}

Received 2017 July 07; Revised 2017 August 10; Accepted 2017 September 20.

\begin{abstract}
Background: Basal cell carcinoma is the most common cancer in humans. The most common cause of this cancer is ultraviolet radiation.

Objectives: The aim of this study was to investigate a possible relationship between the levels of vitamin D and basal cell carcinoma. Methods: In this case-control study, 70 patients with basal cell carcinoma were admitted and registered in the dermatology clinic of Razi hospital in Rasht. The control group included healthy people from the skin clinic or hospital staff matched for gender, skin type, and age. Patients not receiving calcium supplements or vitamin D and not having underlying conditions associated with vitamin $\mathrm{D}$ deficiency were included in this study. The individuals were questioned to complete a demographic questionnaire. Blood samples were taken from all the participants and analyzed for vitamin D, parathyroid hormone, calcium, and phosphorus levels in a reference laboratory. Descriptive statistics and chi-square tests were used to analyze and evaluate the data.

Results: The mean vitamin D level was $24.1 \pm 12.1 \mathrm{ng} / \mathrm{mL}$ in the patient group and $24.6 \pm 11.5 \mathrm{ng} / \mathrm{mL}$ in the control group. Among participants in this study, 49 (35\%) suffered from vitamin D deficiency, 62 (44.3\%) had insufficient vitamin D levels and only $20.7 \%$ had acceptable vitamin D levels. There was no significant difference in vitamin D deficiency between the two groups including controls (34.3\% $(\mathrm{n}=24))$ and patients $(35.7 \%(\mathrm{n}=35))(\mathrm{P}=0.1)$. Also, there was no significant difference between the two groups in terms of other biochemical factors in the blood.

Conclusions: The present study indicates that vitamin D deficiency is highly prevalent in both patients with basal skin cancer and healthy people, which should importantly be considered in future studies.
\end{abstract}

Keywords: Basal Cell Carcinoma, Vitamin D, Ultraviolet Rays

\section{Background}

The most common malignancy in the world is skin cancer, which is associated with high disability and relatively low mortality. Non-melanoma skin cancers are observed in one million people in the United States every year. In addition, basal cell carcinoma is the most common form of skin cancer comprising more than $90 \%$ of American skin cancer cases. This type of cancer almost never spreads to other tissues of the body. However, due to the high incidence and high rate of recurrence, it is the fourth most costly disease to treat in the American health insurance system $(1,2)$. Light skin and sunlight are two important risk factors for basal cell carcinoma. However, about 20\% of these cancers occur in the regions of the body such as the chest, back, arms, legs, and scalp, which are not exposed to sunlight. In recent years, the incidence of skin cancers has increased. According to the results of studies conducted in the Netherlands and the United Kingdom, the reason for this increase can be due to increased daily activities in open environments without adequate coverage of clothes, increased travel to the coast of the seas, long exposure to sunlight, and reduced thickness of the ozone layer $(3,4)$. There is no doubt that ultraviolet radiation is the most common risk factor for non-melanoma skin cancers. One of the best ways to prevent this disease is the protection against sunlight, especially in people at risk. On the other hand, about $90 \%$ of vitamin D required for our body is produced in our skin after the exposure to sun's 
rays. Many studies have shown that vitamin D, in addition to its decisive role in calcium and phosphorus metabolism, has other important roles in autoimmune diseases, cancers, cardiovascular disease, and hypertension. Further ongoing studies might reveal the other roles of vitamin D in future (5-7). One of the commonly raised questions is whether people who use the sunscreens or other sun protection products need to take oral vitamin $\mathrm{D}$ supplements. Studies that have led to a link between vitamin D and skin cancer have faced the dermatologists and public health officials with a big challenge $(8,9)$. However, some new studies have shown that the chance of non-melanoma skin cancers in people with high vitamin D levels is roughly lower around $47 \%$ (2). Therefore, the relationship between the level of vitamin $\mathrm{D}$ and its role in the development of basal cell carcinoma (BCC) is still unrevealed.

\section{Objectives}

In this study, we investigated the possible role of vitamin D in BCC.

\section{Methods}

In our case-control study, 70 newly diagnosed patients with BCC were enrolled when referred to the dermatology clinic of Razi hospital in Rasht. For selecting the control group, patients referring to the skin clinic or the hospital's personnel that matched for gender, skin type, and age were enrolled. The inclusion criteria for the control group were the absence of conditions related to vitamin D deficiencies such as parathyroid, history of surgery, liver, and kidney failure in addition to autoimmune diseases including insulin-dependent diabetes, thyroiditis, rheumatoid arthritis, multiple sclerosis, and lupus erythematosus. In addition, patients who consumed specific medications such as corticosteroids, cholesterol, bisphosphonates, antiacids, thiazide, and anticonvulsants were excluded. Additionally, the following conditions were excluded: suppressive feeding, gastrointestinal malignancy, absorption disturbances such as chronic diarrhea, bile duct disorder, celiac disease, pancreatic diseases, indoor patients, dark skin, alcohol consumption, and herbs. At the first place, both groups were questioned about demographic information and then blood samples were taken from all the subjects participating in this study. The blood samples were analyzed in a reference laboratory for different parameters such as vitamin D, PTH, calcium, and phosphorus levels. Finally, the collected data were analyzed by SPSS Ver. 18 software. A descriptive statistical analysis was used for quantitative and qualitative data and non-parametric tests such as Chi-square were also employed. According to the ethical considerations, the cost of all tests was paid by the research team and all individuals intentionally entered the study.

\section{Results}

In this study, 70 patients were examined in patient and control groups. The mean age of the total study population was $63.5 \pm 13.3$ years $(64.9 \pm 11.9$ years in the patient group and $62.1 \pm 14.5$ years in the control group). The mean difference was not statistically significant between the two groups. In total, $35 \%$ of the study subjects $(n=49)$ had less than $20 \mathrm{ng} / \mathrm{mL}$ vitamin D in their sera including 35.7\% in the patient group $(n=25)$ and $34.3 \%$ in the control group $(n=24)$; the difference was not also statistically significant. Regarding the relationship between the level of vitamin $\mathrm{D}$ and gender of the subjects, it was observed that vitamin $D$ deficiency was slightly higher in men than in women. However, it was not statistically significant (23.5\% vs $38.7 \%$, $\mathrm{P}=0.1$ ). In the patient group, $35.7 \%$ of the subjects suffered from vitamin D deficiency, which was less frequent in women than in men. The difference between the two groups was not statistically significant (18.2\% vs. $43.8 \%, \mathrm{P}>$ 0.05). In the control group, $34.3 \%$ had vitamin D deficiency, and this ratio was lower in men than in women (33.33\% vs. 34.5\%); the difference was not statistically significant ( $P>$ 0.05). The mean levels of vitamin D, PTH, calcium, phosphorus, and other blood factors measured in both groups are presented in Table 1.

\begin{tabular}{|c|c|c|c|}
\hline Blood Factors & $\begin{array}{l}\text { Patient Group, } \\
\text { Mean(SD) }\end{array}$ & $\begin{array}{l}\text { Control Group, } \\
\text { Mean (SD) }\end{array}$ & PValue \\
\hline Vitamin D & $24.11(12.15)$ & $24.63(11.58)$ & 0.7 \\
\hline Parathormon & $53.23(15.45)$ & $51.98(13.04)$ & 0.6 \\
\hline Calcium & $9.54(0.59)$ & $9.36(0.54)$ & 0.7 \\
\hline Phosphorus & $4.52(5.54)$ & $4.03(0.46)$ & 0.4 \\
\hline Hematocrit & $164.46(8.47)$ & $167.46(7.27)$ & 0.3 \\
\hline WT & $66.8(10.9)$ & $67.9(10.0)$ & 0.5 \\
\hline BMI & $24.6(3.8)$ & $24.2(3.5)$ & 0.4 \\
\hline
\end{tabular}

The mean level of vitamin $D$ in all subjects was 24.37 ( $S D=11.11)$, which was $24.11(S D=12.12)$ in the patient group and 23.63 ( $\mathrm{SD}=11.58)$ in the control group. This means that the difference observed between the patient and control groups was not statistically significant $(P>0.05)$. In total, 49 (35\%) patients suffered from vitamin D deficiency, 62 (44.3\%) had insufficient vitamin D and only $20.7 \%$ had ac- 
ceptable vitamin D levels. There were no significant differences in vitamin D deficiency between the two groups as it was around 34.3\% ( $n=24)$ in the control group and 35.7\% (n $=35$ ) in the patient group, shown in Table 2 .

\begin{tabular}{lccc}
\hline \begin{tabular}{l} 
Table 2. Serum Vitamin D Levels in Both the Patient and Control Groups \\
\hline $\begin{array}{l}\text { Serum Vitamin D } \\
\text { Level }\end{array}$
\end{tabular} & Witness, No. (\%) & Patient, No. (\%) & Total, No. (\%) \\
\hline$<\mathbf{2 0}, \mathbf{n g} / \mathbf{m L}$ & $29(48.3)$ & $31(51.7)$ & $60(42.9)$ \\
$\mathbf{2 0}-\mathbf{2 9}, \mathbf{n g} / \mathbf{m L}$ & $29(56.9)$ & $22(43.1)$ & $51(36.4)$ \\
$>\mathbf{3 0}, \mathbf{n g} / \mathbf{m L}$ & $12(41.4)$ & $17(58.6)$ & $29(20.7)$ \\
\hline
\end{tabular}

\section{Discussion}

There is no doubt that ultraviolet radiation is the most common risk factor for non-melanoma skin cancers. One of the best ways to prevent this disease is protection against sunlight, especially in people at risk. More importantly, around $90 \%$ of vitamin D needed for the body is produced when the skin is exposed to sun's rays. Many studies have shown that vitamin $\mathrm{D}$, in addition to its decisive role in calcium and phosphorus metabolism, has other important roles in autoimmune diseases, cancers, cardiovascular disease, and hypertension. Moreover, there is much ongoing research to investigate the various roles of this vitamin (5-7). Some novel investigations have shown that the chance of non-melanoma skin cancers in people with high vitamin D levels is lower as much as $47 \%$ (2). There was no significant difference in the serum level of vitamin $D$ between the patient and control groups, which is not consistent with other studies in this area (2,10-19). This may be due to an increase in the ratio of vitamin D deficiency in the general population, which caused no significant differences. Based on investigations on vitamin D deficiency in different parts of Iran, the following data have been found: $70.5 \%$ in Isfahan $(n=15), 78.6 \%$ in Sari $(n=16), 40-69 \%$ in North Khorasan $(n=17), 79 \%$ in Tehran $(n=18), 84 \%$ in $\operatorname{Arak}(n=19), 85.2 \%$ in Zahedan $(n=20)$, and $84.7 \%$ in postmenopausal women in Guilan $(n=21)$. These studies highlight the high incidence of vitamin D deficiency in various regions of Iran including temperate and very hot areas. Moreover, lifestyle and nutrition change seems to be beneficial for vitamin D deficiency since most people are deprived of solar radiation. This is while lifestyle has changed from agriculture to office work that requires staying out of the sun. On the other hand, transportation is carried out more than ever by car and children playgrounds are in indoor environments and away from contact with sunlight. Modern food also contains less vitamin D. Therefore, it seems that an alternative should be considered as soon as possible, such as educating people, creating outdoor playgrounds for students and children, changing diet, or adding this vitamin to the permanent food of people like water, bread, salt, or dairy. Altogether, in the present study, there were no significant differences in terms of vitamin D deficiency level between males and females. However, in other parts of Iran, vitamin D deficiency was more common in women than in men. Perhaps this could be because of the study sample that was not high enough to generalize the results to the whole society. It is also possible that the lack of this vitamin in men in this area is as high as in women, which requires more extensive studies based on the general population in future.

\subsection{Conclusion}

The present study indicated that vitamin D deficiency was high in both the patients with basal skin cancer and healthy individuals, which needs further study to understand the reasons for this rate of vitamin D deficiency in Guilan province as it is crucial for following probable therapeutic approaches. Accordingly, the bigger sample size is certainly required for further investigation in Guilan.

\section{References}

1. Mackie RM, Quinn AG. Non-Melanoma Skin Cancer and Other Epidermal Skin Tumours. In: Burns T, Breathnach S, Cox N, Griffiths C, editors. Rook's Textbook of Dermatology. 7 ed. Oxford: Blackwell Science Publication; 2004. p. 1801-50.

2. Tang JY, Parimi N, Wu A, Boscardin WJ, Shikany JM, Chren MM, et al. Inverse association between serum $25(\mathrm{OH})$ vitamin D levels and non-melanoma skin cancer in elderly men. Cancer Causes Control. 2010;21(3):387-91. doi: 10.1007/s10552-009-9470-4. [PubMed: 19921445]. [PubMed Central: PMC2835729].

3. Harris RB, Alberts DS. Strategies for skin cancer prevention. Int J Dermatol. 2004;43(4):243-51. doi: 10.1111/j.1365-4632.2004.01966.x. [PubMed: 15090005].

4. James WD, Elston D, Berger T. Andrew's Diseases of the Skin E-Book: Clinical Dermatology. 11 ed. Saunders: Elsevier Health Sciences; 2011.

5. Reichrath J. The challenge resulting from positive and negative effects of sunlight: how much solar UV exposure is appropriate to balance between risks of vitamin D deficiency and skin cancer? Prog Biophys Mol Biol. 2006;92(1):9-16. doi: 10.1016/j.pbiomolbio.2006.02.010. [PubMed: 16603232].

6. Garland CF, Garland FC, Gorham ED, Lipkin M, Newmark H, Mohr $\mathrm{SB}$, et al. The role of vitamin D in cancer prevention. Am J Public Health. 2006;96(2):252-61. doi: 10.2105/AJPH.2004.045260. [PubMed: 16380576]. [PubMed Central: PMC1470481].

7. Holick MF. Vitamin D and sunlight: strategies for cancer prevention and other health benefits. Clin J Am Soc Nephrol. 2008;3(5):154854. doi: 10.2215/CJN.01350308. [PubMed: 18550652]. [PubMed Central: PMC4571149].

8. Scarlett WL. Ultraviolet radiation: sun exposure, tanning beds, and vitamin D levels. What you need to know and how to decrease the risk of skin cancer. J Am Osteopath Assoc. 2003;103(8):371-5. [PubMed: 12956250]. 
9. Reichrath J, Nurnberg B. Cutaneous vitamin D synthesis versus skin cancer development: The Janus faces of solar UV-radiation. Dermatoendocrinol. 2009;1(5):253-61. [PubMed: 20808512]. [PubMed Central: PMC2836430].

10. Gandini S, Raimondi S, Gnagnarella P, Dore JF, Maisonneuve P, Testori A. Vitamin D and skin cancer: a meta-analysis. Eur J Cancer. 2009;45(4):634-41. doi: 10.1016/j.ejca.2008.10.003. [PubMed: 19008093].

11. Asgari MM, Tang J, Warton ME, Chren MM, Quesenberry CPJ, Bikle D, et al. Association of prediagnostic serum vitamin D levels with the development of basal cell carcinoma. Invest Dermatol. 2010;130(5):143843. doi: 10.1038/jid.2009.402. [PubMed: 20043012]. [PubMed Central: PMC2855394].

12. Lamberg AL, Olesen $A B$, Jensen AO. Hip fracture history and risk of nonmelanoma skin cancer: a Danish population-based study. Clin Epidemiol. 2011;3:285-93. doi: 10.2147/CLEP.S25650. [PubMed: 22135503]. [PubMed Central: PMC3224634].

13. Hovsepian S, Amini M, Aminorroaya A, Amini P, Iraj B. Prevalence of vitamin D deficiency among adult population of Isfahan City, Iran. J Health Popul Nutr. 2011;29(2):149-55. [PubMed: 21608424]. [PubMed Central: PMC3126987].

14. Kashi Z, Saeedian F, Akha O, Gorgi M, Emadi S, Zakeri H. Vitamin D deficiency prevalence in summer compared to winter in a city with high humidity and a sultry climate. Endokrynol Pol. 2011;62(3):249-51.
[PubMed: 21717408].

15. Habibesadat S, Ali K, Shabnam JM, Arash A. Prevalence of vitamin D deficiency and its related factors in children and adolescents living in North Khorasan, Iran. J Pediatr Endocrinol Metab. 2014;27(5-6):431-6. doi: 10.1515/jpem-2013-0198. [PubMed: 24519715].

16. Kelishadi R, Ardalan G, Motlagh ME, Shariatinejad K, Heshmat R, Poursafa $\mathrm{P}$, et al. National report on the association of serum vitamin $\mathrm{D}$ with cardiometabolic risk factors in the pediatric population of the Middle East and North Africa (MENA): the CASPIAN-III Study. Nutrition. 2014;30(1):33-8. doi: 10.1016/j.nut.2013.05.018. [PubMed: 24290595].

17. Talaei A, Yadegari N, Rafee M, Rezvanfar MR, Moini A. Prevalence and cut-off point of vitamin D deficiency among secondary students of Arak, Iran in 2010. Indian J Endocrinol Metab. 2012;16(5):786-90. doi:10.4103/2230-8210.100676. [PubMed: 23087865]. [PubMed Central: PMC3475905].

18. Kaykhaei MA, Hashemi M, Narouie B, Shikhzadeh A, Rashidi H, Moulaei N, et al. High prevalence of vitamin D deficiency in Zahedan, southeast Iran. Ann Nutr Metab. 2011;58(1):37-41. doi: 10.1159/000323749. [PubMed: 21304235].

19. Maddah M, Sharami SH, Neyestani TR. Vitamin D insufficiency among postmenopausal women in urban and rural areas in Guilan, Northern Iran. J Nutr Elder. 2009;28(4):386-93. doi: 10.1080/01639360903393523. [PubMed: 21184380]. 